\title{
Implementasi Load Balancing Web Server \\ Menggunakan Metode LVS-NAT
}

\author{
Jefry Alvonsius Rabu ${ }^{1}$ \\ jefryrabu@gmail.com
}

\author{
Joko Purwadi ${ }^{2}$ \\ jokop@ukdw.ac.id
}

\author{
Willy S. Raharjo ${ }^{3}$ \\ willysr@ti.ukdw.ac.id
}

\begin{abstract}
Web server plays a vital role on serving requests from clients. As Internet users grows so fast, the request number increases significantly, thus reducing the overall performance of the web server. One solution is to implement a load balancing system.In this paper, we implement load balancing with Linux Virtual Server to distribute the load to several machines within a cluster. We compared Round Robbin and Least Connection algorithm.

The study reveals that load balancing using LVS-NAT can double the throughput output compared to single web server, but less significant on response time and CPU utilization. Implementing LVS-NAT using round robbin algorithm is more robust in optimizing the throughput, CPU utilization, and response time compared to least connection.
\end{abstract}

Kata Kunci : Web Server, Load Balancing, LVS-NAT, Round Robbin, Least Connection

\section{PENDAHULUAN}

Salah satu jenis layanan dari internet yaitu World Wide Web. World Wide Web atau web adalah suatu cara mengakses informasi melalui media internet. Web bisa juga dikatakan sebagai suatu model berbagi informasi yang dibangun di atas media internet. Web menggunakan protokol HTTP untuk mengirimkan data. Data tersebut tersebar di seluruh penjuru dunia disimpan dalam media penyimpananan berupa server. Web server bertanggung jawab melayani permintaan HTTP dari aplikasi klien yang dikenal dengan web browser. Web server akan mencari data dari Uniform Resource Locator (URL) yang diminta dan mengirimkan kembali hasilnya dalam bentuk halaman-halaman web yang umumnya berbentuk dokumen Hypertext Markup Language (HTML) dan semua isi (content) dari suatu situs ke komputer klien.

Seiring dengan berkembangnya kebutuhan pengguna dan peningkatan permintaan pada situs maka kerja dari web server bertambah berat. Web server yang handal selayaknya mampu melayani request dari pengguna dalam jumlah yang cukup besar dalam satu satuan

\footnotetext{
${ }^{1}$ Teknik Informatika, Fakultas Teknologi Informasi, Universitas Kristen Duta Wacana, Yogyakarta

${ }^{2}$ Teknik Informatika, Fakultas Teknologi Informasi, Universitas Kristen Duta Wacana, Yogyakarta

${ }^{3}$ Teknik Informatika, Fakultas Teknologi Informasi, Universitas Kristen Duta Wacana, Yogyakarta
} 
waktu. Namun terkadang web server mengalami down atau fail dimana web server tidak dapat mampu lagi menangani jumlah request yang sangat besar dalam satu satuan waktu tersebut.

Salah satu solusi yang dapat dilakukan untuk mengatasi masalah performa web server dalam hubungannya dengan jumlah request yang meningkat adalah pemutakhiran perangkat keras web server, namun solusi ini hanya bersifat sementara. Maka dengan ini perlu diterapkan suatu implementasi teknologi yang dapat menjadi solusi alternatif masalah di atas. Teknik yang dianjurkan pada penelitian ini adalah implementasi load balancing dimana beban kerja single server dibagi ke dalam beberapa server yang ada.

\section{DASAR TEORI}

\subsection{Web Server.}

Gourley,et al.(2002), dalam bukunya yang berjudul "HTTP - The Definitive Guide" menjelaskan bahwa web server dapat mengacu kepada perangkat lunak maupun perangkat keras tertentu atau komputer yang memuat halaman - halaman web. Sebuah web server bertugas memproses HTTP request dan memberikan respon terhadap request tersebut.

Menurut Mitch Tulloch dalam "Microsoft Encyclopedia of Networking" web server didefenisikan sebagai suatu aplikasi yang mendukung Hypertext Transfer Protocol (HTTP) pada sisi server. Web server digunakan untuk mem-publish konten pada intranet perusahaan tertentu atau melalui jaringan internet. Web server menyimpan konten dari sebuah web. Web server bekerja menggunakan protokol HTTP oleh karena itu sering kali disebut HTTP server.

\subsection{Uji Performansi Web Server.}

Uji performansi web server memiliki bentuk-bentuk tersendiri sebagai berikut:

- Performance Test.

Uji performansi digunakan untuk menguji setiap bagian dari suatu web server dengan tujuan untuk menemukan teknik terbaik mencapai optimasi ketika trafik web meningkat.

- Load Test.

Load test dilakukan dengan pengujian website menggunakan estimasi trafik dari sebuah website yang mampu dilayani. Caranya adalah mendefinisikan waktu maksimum sebuah halaman web dimuat. Pada akhir pengujian dilakukan pembandingan seberapa maksimum waktu yang dibutuhkan untuk membuka halaman web pada sebuah web server.

- Stress Test. 
Stress test adalah berupa simulasi serangan "brute force" yang menjalankan muatan atau permintaan secara berlebihan menuju web server. Tujuan stress test adalah untuk mengestimasi muatan maksimum sebuah web server sanggup menanganinya.

\subsection{Load Balancing.}

Server load balancing adalah sebuah proses atau teknologi yang mendistribusikan trafik sebuah situs kepada beberapa server menggunakan sebuah perangkat jaringan. Perangkat tersebut menerima trafik yang ditujukan pada suatu situs dan mendistribusikannya ke beberapa server. Proses load balancing sepenuhnya transparan bagi end-user. Load balancing dapat diimplementasikan dengan hardware khusus, software maupun gabungan keduanya. Konfigurasi standar yang ada memberi gambaran bahwa satu mesin ditempatkan diantara klien dan server, mesin ini disebut sebagai director karena tugasnya adalah memberikan balancing pada request dari klien ke server. Sebuah load balancer adalah perangkat jaringan yang dipasang diantara klien dan server, bekerja sebagai saklar untuk request dari klien. Load balancer mengimplementasikan beberapa metode penjadwalan yang akan menentukan ke arah server mana request dari klien akan diteruskan. Beberapa keuntungan yang diperoleh dari teknik load balancing sebagai berikut:

- Flexibility : Server tidak lagi menjadi inti sistem dan resource utama, tetapi menjadi bagian dari banyak server yang membentuk cluster. Hal ini berarti bahwa performa per unit dari cluster tidak terlalu diperhitungkan, tetapi performa cluster secara keseluruhan. Sedangkan untuk meningkatkan performa dari cluster, server atau unit baru dapat ditambahkan tanpa mengganti unit yang lama.

- Scalability : Sistem tidak memerlukan desain ulang seluruh arsitektur sistem untuk mengadaptasikan sistem tersebut ketika terjadi perubahan pada komponen sistem.

- Security : Untuk semua trafik yang melewati load balancer, aturan keamanan dapat dimplementasikan dengan mudah. Dengan private network digunakan untuk real servers, alamat IPnya tidak akan diakses secara langsung dari luar sistem cluster.

- High-availability : Load balancer dapat mengetahui kondisi real server dalam sistem secara otomatis, jika terdapat real server yang mati maka akan dihapus dari daftar real server, dan jika real server tersebut kembali aktif maka akan dimasukkan ke dalam daftar real server. Load balancer juga dapat dikonfigurasi redundant dengan load balancer yang lain.

\subsection{Linux Virtual Server.}

Virtual server adalah server yang mempunyai skalabilitas dan ketersedian yang tinggi yang dibangun diatas sebuah cluster dari beberapa real server. Arsitektur dari sebuah 
server cluster adalah benar-benar transparan sampai ke end-user dan masing-masing user berinteraksi dengan sistem seolah-olah hanya ada satu virtual server dengan performa yang tinggi.

Linux Virtual Server (LVS) menerapkan proses pemilihan pada layer 4 (Transport) dari kernel Linux. LVS meneruskan session TCP dan UDP untuk menyeimbangkan beban melalui beberapa real server. LVS berjalan pada Linux dan dapat menyeimbangkan koneksi dari end-user dengan sistem operasi apapun kepada real-server yang menjalankan sistem operasi apapun, selama koneksi yang dilakukan menggunakan TCP atau UDP. Linux virtual server (LVS) adalah alternatif utama open source yang menyediakan solusi untuk menciptakan sistem load balancing. Seperti yang ditulis di home site Linux Virtual Server project, "Linux virtual server is a highly scalable and highly available server built on a cluster of real servers, with the load balancer running on the linux operating system".

Linux Virtual server dapat dimplementasikan dalam tiga cara. Ada tiga teknik IP load balancing dalam sebuah load balancer, yaitu :

- Network Address Transrlation (NAT) :

Suatu metode yang memanipulasi alamat IP dan nomor port baik sumber maupun tujuannya. Alamat IP publik disamarkan untuk digunakan oleh alamat IP private agar bisa berhubungan dengan dunia luar (internet). Semua proses masuk (end-user) dan keluarnya (real server) paket harus melalui satu alamat IP publik saja (director/load balancer/virtual server).

- Direct Routing :

Paket dari end-user diteruskan secara langsung ke real server. IP paket tidak dimodifikasi, jadi real server harus dikonfigurasi untuk menerima trafik dari alamat IP load balancer.

- IP Tunneling :

Metode IP tunneling melewatkan alamat paket kepada alamat IP untuk diarahkan kepada alamat yang lain, hal ini mungkin dilakukan pada jaringan yang berbeda. Pada proses pemilihan di layer 4 cara ini hampir sama dengan Direct Routing, hanya saja ketika paket diteruskan paket tersebut dibungkus pada paket IP kemudian memanipulasi frame ethernet.

\section{TOPOLOGI PENELITIAN}

\subsection{Topologi Penelitian.}

Pada penelitian ini digunakan 2 bentuk topologi masing - masing untuk mengukur performa web server tunggal (Gambar 1) dan web server dengan implementasi load balancing LVS-NAT (Gambar 2). 


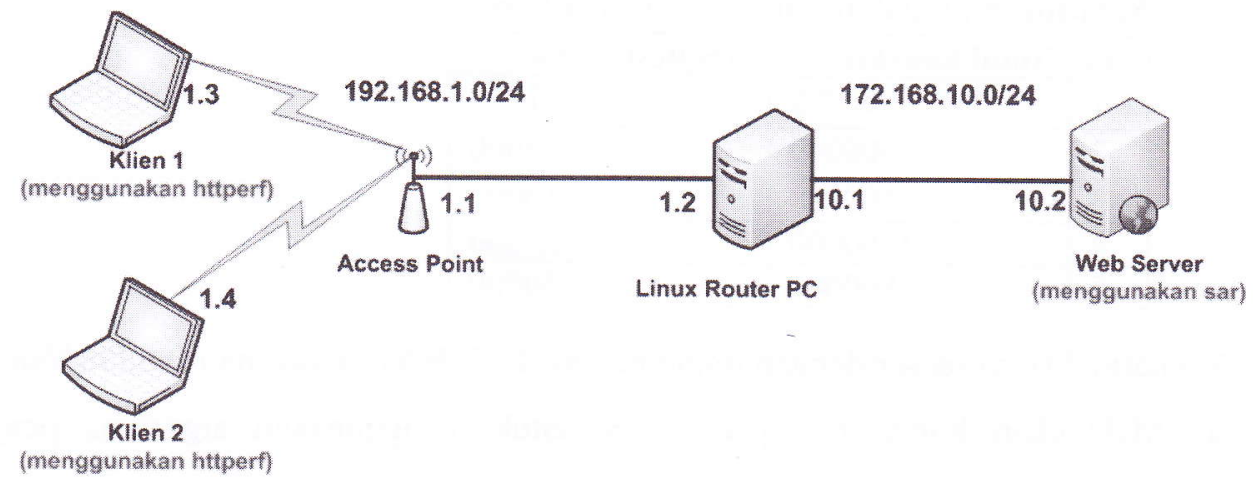

Gambar 1. Topologi Pengujian Web Server Tunggal.

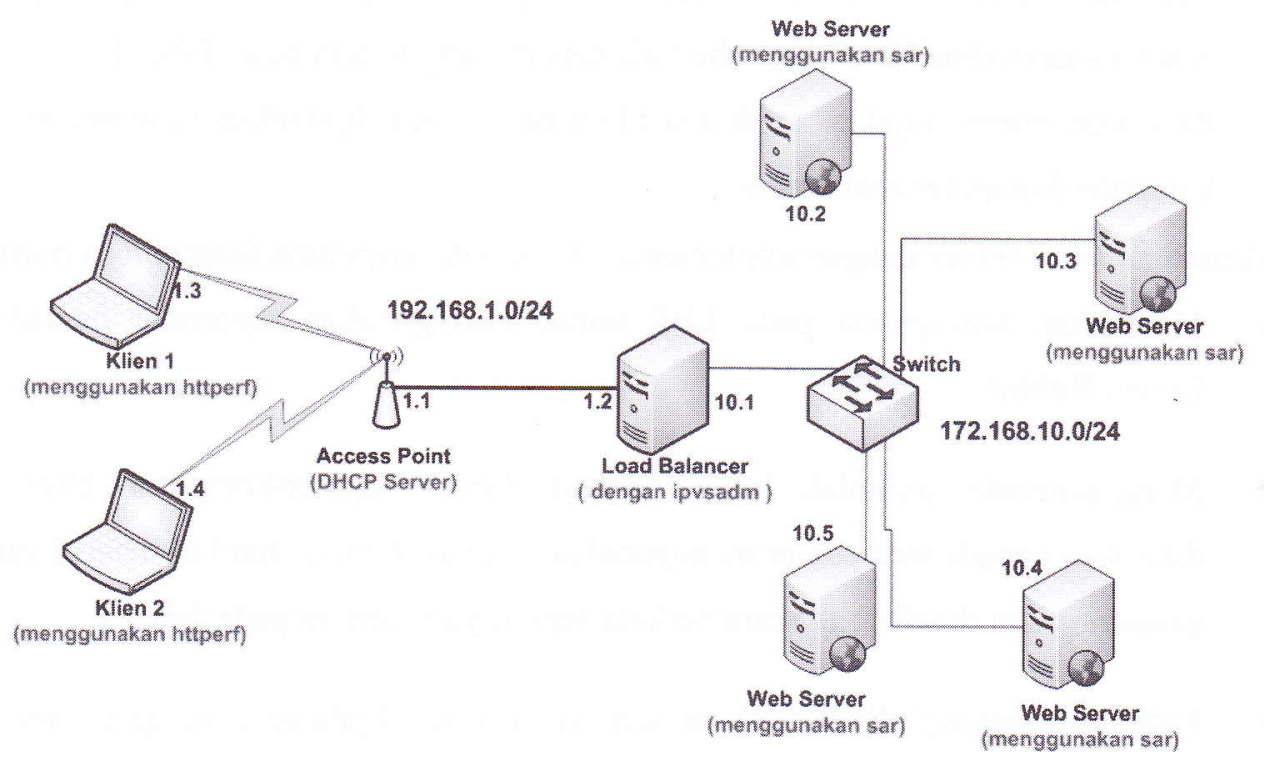

Gambar 2. Topologi Pengujian Web Server dengan Implementasi LVS.

\subsection{Skenario Pengambilan Sampel.}

Untuk mengukur kinerja dari web server tanpa implementasi load balancing dan kinerja web server dengan implementasi load balancing maka akan dilakukan beberapa skenario pengujian dengan menggunakan aplikasi-aplikasi pendukung.

1. Skenario 1 (web server tunggal tanpa loab balancing).

a. Meng-generate sejumlah besar request dari komputer-komputer klien yang ditujukan kepada web server menggunakan aplikasi httperf. Jumlah request yang di-generate akan dinaikkan secara berkala seperti yang tertera pada tabel 1.

b. Pada saat httperf dijalankan di sisi klien maka dijalankan juga program sar pada komputer-komputer real server. 
Tabel 1.

Rancangan jumlah beban request pada httperf.

\begin{tabular}{|r|r|r|}
\hline No. & Total koneksi & Request/second \\
\hline 1 & 60000 & 1000 \\
\hline 2 & 300000 & 5000 \\
\hline 3 & 600000 & 10000 \\
\hline 4 & 1200000 & 20000 \\
\hline 5 & 1800000 & 30000 \\
\hline
\end{tabular}

2. Skenario 2 (web server dengan implementasi LVS-NAT algoritma round robbin).

a. Melakukan konfigurasi pada LVS untuk menggunakan algoritma penjadwalan Round Robbin.

b. Meng-generate sejumlah besar request dari komputer-komputer klien yang ditujukan kepada web server menggunakan aplikasi httperf. Jumlah request yang digenerate akan dinaikkan secara berkala seperti yang tertera pada Tabel 1.

c. Pada saat httperf dijalankan di sisi klien maka juga dijalankan program sar pada komputer-komputer real server.

3. Skenario 3 (web server dengan implementasi LVS-NAT algoritma least connection).

a. Melakukan konfigurasi pada LVS untuk menggunakan algoritma penjadwalan Round Robbin.

b. Meng-generate sejumlah besar request dari komputer-komputer klien yang ditujukan kepada web server menggunakan aplikasi httperf. Jumlah request yang digenerate akan dinaikkan secara berkala seperti yang tertera pada Tabel 1.

c. Pada saat httperf dijalankan di sisi klien juga dijalankan program sar pada komputer-komputer real server.

\section{PENGAMATAN}

Pengamatan dalam penelitian ini dilakukan dalam 3 parameter yaitu throughput, response time, dan CPU Utilization. Pengamatan dilakukan pada 2 sisi untuk ketiga parameter tersebut yaitu pada sisi klien melalui tool httperf untuk melihat throughput dan response time dan pada sisi real server melalui sar untuk melihat utilitas CPU.

\subsection{Analisis Hasil Pengamatan,}

\subsubsection{Analisis Hasil Pengamatan Parameter Throughput.}

Pengamatan parameter throughput dilakukan di sisi klien menggunakan httperf. Nilai throughput pada penelitian ini mewakili jumlah request klien yang dapat direspon oleh web server dalam satu satuan waktu. Semakin besar nilai throughput yang dihasilkan menunjukkan bahwa kinerja web server tersebut semakin baik karena semakin banyak 
request klien yang dapat direspon oleh suatu web server dalam satu satuan waktu. Hasilnya dapat dilihat pada tabel 2 .

Tabel 2.

Perbandingan Throughput (Replies/Second).

\begin{tabular}{|c|c|c|c|c|}
\hline \multirow{2}{*}{$\begin{array}{l}\text { Jumlah Koneksi } \\
\text { (Request Rate) }\end{array}$} & \multirow{2}{*}{$\begin{array}{l}\text { server } \\
\text { tunggal }\end{array}$} & \multicolumn{3}{|c|}{$\begin{array}{c}\text { Web Server Dengan Implementasi Load } \\
\text { balancing LVS-NAT }\end{array}$} \\
\hline & & 2 server $\mathrm{rr}$ & 2 server lc & 4 server $\mathrm{rr}$ \\
\hline $\begin{array}{c}60.000 \\
\text { (1.000request/second) }\end{array}$ & 41.5 & 49.5 & 67.7 & 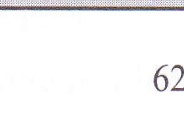 \\
\hline $\begin{array}{c}\text { (5.000request/second) } \\
600.000\end{array}$ & 31.8 & 60.1 & 39.5 & 32.9 \\
\hline $\begin{array}{c}\text { (10.000request/second) } \\
1.200 .000\end{array}$ & 37.1 & 59.3 & 42.8 & 39.9 \\
\hline $\begin{array}{c}\text { (20.000 request/second) } \\
1.800 .000\end{array}$ & 35.3 & 44.9 & 44.9 & 149.9 \\
\hline (30.000 request/second) & 14.9 & 55.1 & 30.5 & 61.7 \\
\hline Rata-rata & 32.12 & 53.78 & 45.08 & 69.28 \\
\hline
\end{tabular}

Keterangan :

- 2 server rr : LVS-NAT algoritma round robbin dengan 2 real server.

- $\quad 2$ server lc : LVS-NAT algoritma least connection dengan 2 real server.

- 4 server rr : LVS-NAT algoritma round robbin dengan 4 real server.

- 4 server lc : LVS-NAT algoritma least connection dengan 4 real server.

Hasil Analisis :

a. Web server tunggal hanya mampu menghasilkan rata-rata 32,12 replies/second. Nilai ini lebih kecil dibandingkan dengan web server yang telah menerapkan load balancing menggunakan LVS-NAT yaitu LVS-NAT 2 server algoritma least connection 45,08 replies/second, LVS-NAT 4 server algoritma least connection 47,96 replies/second, LVS-NAT 2 server round robbin 53,78 replies/second, dan LVS-NAT 4 server round robbin 69,28 replies/second. Hal ini menunjukkan bahwa throughput web server dengan implementasi load balancing menggunakan LVS-NAT lebih baik dibandingkan throughput web server tunggal.

b. Web server dengan implementasi load balancing LVS-NAT menggunakan algoritma round robbin menunjukkan throughput yang lebih baik dibandingkan dengan LVS-NAT algoritma least connection. Hal ini dapat dilihat baik pada implementasi load balancing dengan 2 server maupun 4 server. Nilai throughput LVS-NAT least connection 2 server 45,08 replies/second lebih kecil dari nilai throughput LVS-NAT round robbin 2 server 53,78 replies/second. 
Nilai throughput LVS-NAT least connection 4 server 47,96 replies/second lebih kecil dari nilai throughput LVS-NAT round robbin 4 server 69,28 replies/second.

c. Nilai throughput web server dengan implementasi load balancing LVS-NAT 4 server 69,28 replies/second merupakan nilai throughput terbaik.

\subsubsection{Analisis Hasil Pengamatan Parameter Response Time.}

Pengamatan parameter response time dilakukan di sisi klien menggunakan httperf. Nilai response time pada penelitian ini mewakili kecepatan web server dalam menanggapi request klien. Semakin kecil nilai response time yang dihasilkan menunjukkan semakin cepatnya web server menanggapi request dari klien. Hasilnya dapat dilihat pada tabel 3.

Tabel 3.

Perbandingan Response Time (microsecond)

\begin{tabular}{|c|c|c|c|c|}
\hline \multirow{2}{*}{$\begin{array}{l}\text { Jumlah Koneksi } \\
\text { (Request Rate) }\end{array}$} & \multirow[t]{2}{*}{ server tunggal } & \multicolumn{3}{|c|}{$\begin{array}{l}\text { Web Server Dengan Implementasi Load } \\
\text { balancing LVS-NAT }\end{array}$} \\
\hline & & 2 server $\mathrm{rr}$ & 2 server lc & 4 server $\mathrm{rr}$ \\
\hline $\begin{array}{c}60.000 \\
(1.000 \text { request/second })\end{array}$ & 2089.2 & 2436.2 & 2257.6 & 2141.5 \\
\hline $\begin{array}{l}\text { (5.000 request/second) } \\
600.000\end{array}$ & 2633.5 & 2286.1 & 2507.8 & 2649.4 \\
\hline $\begin{array}{c}(10.000 \text { request/second }) \\
1.200 .000\end{array}$ & 2361.4 & 2147.4 & 2480.9 & 2789.1 \\
\hline $\begin{array}{c}\text { (20.000 request/second) } \\
1.800 .000\end{array}$ & 2119.3 & 2265.2 & 2545.5 & 1519.8 \\
\hline (30.000 request/second) & 3628.4 & 2354.5 & 2827.6 & 2364.8 \\
\hline Rata-rata & 2566.36 & 2297.88 & 2523.88 & 2292.92 \\
\hline
\end{tabular}

Keterangan :

- 2 server rr

- 2 server lc

: LVS-NAT algoritma round robbin dengan 2 real server.

- 4 server rr : LVS-NAT algoritma least connection dengan 2 real server.

- 4 server lc : LVS-NAT algoritma round robbin dengan 4 real server. : LVS-NAT algoritma least connection dengan 4 real server.

Hasil Analisis :

a. Nilai response time web server tunggal 2566,36 ms merupakan yang terbesar dibandingkan web server LVS-NAT 4 server least connection 2528,72 ms, web server LVS-NAT 2 server least connection 2523,88 ms, web server LVS-NAT round robbin 2 server $2297,88 \mathrm{~ms}$, dan web server LVS-NAT round robbin 4 server 2292,92 ms. Hal ini menunjukkan bahwa penerapan load balancing menggunakan LVS-NAT bisa meningkatkan kecepatan web server menanggapi request klien. 
b. Nilai response time web server dengan implementasi load balancing metode LVS-NAT algoritma round robbin 2297,88 ms untuk 2 server dan 2292,92 ms untuk 4 server memiliki nilai response time yang lebih baik dari web server dengan implementasi LVS-NAT menggunakan algoritma least connection $2523,88 \mathrm{~ms}$ untuk 2 server dan $2528,72 \mathrm{~ms}$ untuk 4 server.

\subsubsection{Analisis Hasil Pengamatan Parameter CPU Utilization.}

Pengamatan parameter CPU Utilization dilakukan di sisi server menggunakan sar. Nilai CPU Utilization diperoleh dari nilai seluruh sumber daya CPU yang ada yaitu 100\% dikurangi persentasi sumber daya tersisa pada kolom \% idle output sar. Semakin besar nilai hasil pengurangan tersebut maka semakin baik karena semakin optimal server tersebut bekerja dan menggunakan sumber daya yang ada. Hasilnya dapat dilihat pada tabel 4, 5, 6, 7 , dan 8 .

Tabel 4.

Persentasi CPU Utilization Web Server Tunggal

\begin{tabular}{|r|r|}
\hline $\begin{array}{r}\text { Jumlah Koneksi } \\
\text { (Request Rate) }\end{array}$ & server tunggal \\
\hline $\begin{array}{r}60.000(1.000 \\
\text { request/second) } \\
300.000(5.000\end{array}$ & 94.47 \\
$\begin{array}{r}\text { request/second) } \\
600.000(10.000 \\
\text { request/second) }\end{array}$ & 95.6 \\
$1 \begin{array}{r}200.000(20.000 \\
\text { request/second) } \\
1.800 .000(30.000 \\
\text { request/second) }\end{array}$ & 95.11 \\
\hline Rata-rata & 94.65 \\
\hline
\end{tabular}

Sumber daya CPU yang digunakan $=100 \%-95.07 \%=4.93 \%$

Tabel 5.

Persentasi CPU Utilization Web Server Dengan LVS-NAT Algoritma RR menggunakan 2 Real Server

\begin{tabular}{|c|r|r|}
\hline $\begin{array}{c}\text { Jumlah Koneksi } \\
\text { (Request Rate) }\end{array}$ & server 1 & \multicolumn{1}{|c|}{ server 2 } \\
\hline $60.000(1.000$ request/second) & 95.71 & 95.87 \\
$300.000(5.000$ request/second) & 95.72 & 96.05 \\
$600.000(10.000$ request/second) & 95.70 & 95.85 \\
$1.200 .000(20.000$ request/second) & 96.21 & 96.40 \\
$1.800 .000(30.000$ request/second) & 95.56 & 95.66 \\
\hline Rata-rata & 95.78 & 95.97 \\
\hline
\end{tabular}


Sumber daya CPU yang digunakan pada server $1=100 \%-95.78 \%=4.22 \%$ Sumber daya CPU yang digunakan pada server $2=100 \%-95.97 \%=4.03 \%$

Tabel 6.

Persentasi CPU Utilization Web Server Dengan LVS-NATAlgoritma LC menggunakan 2 Real Server

\begin{tabular}{|r|r|r|}
\hline $\begin{array}{c}\text { Jumlah Koneksi } \\
\text { (Request Rate) }\end{array}$ & server $\mathbf{1}$ & \multicolumn{1}{c|}{ server $\mathbf{2}$} \\
\hline $60.000(1.000$ request/second) & 95.61 & 96.22 \\
$300.000(5.000$ request/second) & 95.87 & 96.18 \\
$600.000(10.000$ request/second) & 95.46 & 96.78 \\
$1.200 .000(20.000$ request/second) & 96.63 & 96.36 \\
$1.800 .000(30.000$ request/second) & 97.07 & 96.60 \\
\hline Rata-rata & 96.13 & 96.43 \\
\hline
\end{tabular}

Sumber daya CPU yang digunakan pada server $1=\mathbf{1 0 0} \%-\mathbf{9 6 . 1 3} \%=\mathbf{3 . 8 7} \%$

Sumber daya CPU yang digunakan pada server $2=\mathbf{1 0 0} \%-\mathbf{9 6 . 4 3} \%=\mathbf{3 . 5 7} \%$

Tabel 7.

Persentasi CPU Utilization Web Server Dengan LVS-NAT Algoritma RR menggunakan 4 Real Server

\begin{tabular}{|c|c|c|c|c|}
\hline $\begin{array}{c}\text { Jumlah Koneksi } \\
\text { (Request Rate) }\end{array}$ & server 1 & server 2 & server 3 & server 4 \\
\hline $\begin{array}{c}60.000 \\
(1.000 \mathrm{request} / \text { second })\end{array}$ & 97.52 & 96.47 & 97.04 & 97.27 \\
\hline 300.000 & & & & 0606 \\
\hline $\begin{array}{c}\text { (5.000 request/second) } \\
600.000\end{array}$ & 97.43 & 96.94 & 97.15 & 96.96 \\
\hline (10.000 request/second) & 97.55 & 96.96 & 96.65 & 97.07 \\
\hline (20.000 request/second) & 97.37 & 96.55 & 96.54 & 96.71 \\
\hline $\begin{array}{c}1.800 .000 \\
(30.000 \mathrm{request} / \mathrm{second})\end{array}$ & 97.51 & 96.60 & 96.82 & 97.01 \\
\hline Rata-rata & 97.48 & 96.70 & 96.84 & 97.00 \\
\hline
\end{tabular}

Sumber daya CPU yang digunakan pada server $1=\mathbf{1 0 0} \%-\mathbf{9 7 . 4 8} \%=\mathbf{2 . 5 2} \%$

Sumber daya CPU yang digunakan pada server $2=\mathbf{1 0 0} \%-\mathbf{9 6 . 7 0} \%=\mathbf{3 . 3} \%$

Sumber daya CPU yang digunakan pada server $3=100 \%-96.84 \%=3.16 \%$

Sumber daya CPU yang digunakan pada server $4=\mathbf{1 0 0} \%-\mathbf{9 7} \%=\mathbf{3} \%$

\section{Tabel 8.}

Persentasi CPU Utilization Web Server Dengan LVS-NAT Algoritma LC menggunakan 4 Real Server

\begin{tabular}{|c|r|r|r|r|}
\hline $\begin{array}{c}\text { Jumlah Koneksi } \\
\text { (Request Rate) }\end{array}$ & server 1 & server 2 & server 3 & server 4 \\
\hline $\begin{array}{c}60.000 \\
(1.000 \text { request/second) }\end{array}$ & 97.56 & 97.70 & 97.20 & 97.17 \\
\hline
\end{tabular}


Tabel 8.

Persentasi CPU Utilization Web Server Dengan LVS-NAT Algoritma LC menggunakan 4 Real Server

\begin{tabular}{|c|r|r|r|r|}
\hline $\begin{array}{c}\text { Jumlah Koneksi } \\
\text { (Request Rate) }\end{array}$ & server 1 & server 2 & server 3 & server 4 \\
\hline $\begin{array}{c}300.000 \\
(5.000 \text { request/second) } \\
600.000\end{array}$ & 97.67 & 97.72 & 96.51 & 96.51 \\
$(10.000$ request/second) & 97.51 & 97.95 & 97.51 & 97.6 \\
$\begin{array}{c}1.200 .000 \\
(20.000 \text { request/second) } \\
1.800 .000\end{array}$ & 97.37 & 97.72 & 97.54 & 97.77 \\
$(30.000$ request/second) & 97.68 & 98.45 & 96.99 & 96.53 \\
\hline Rata-rata & 97.56 & 97.91 & 97.15 & 97.12 \\
\hline
\end{tabular}

Sumber daya CPU yang digunakan pada server $1=\mathbf{1 0 0} \% \mathbf{- 9 7 . 5 6}=\mathbf{2 . 4 4} \%$

Sumber daya CPU yang digunakan pada server $2=\mathbf{1 0 0} \%-\mathbf{9 7 . 9 1}=\mathbf{2 . 0 9} \%$

Sumber daya CPU yang digunakan pada server $3=\mathbf{1 0 0} \%-\mathbf{9 7 . 1 5} \%=\mathbf{2 . 8 5} \%$

Sumber daya CPU yang digunakan pada server $4=\mathbf{1 0 0} \%-\mathbf{9 7 . 1 2} \%=\mathbf{2 . 8 8} \%$

Hasil analisis :

a. Web server tunggal paling banyak memakan sumber daya CPU sebesar $4,93 \%$ atau hampir 5\% sedangkan web server yang telah menerapkan load balancing menggunakan LVS-NAT hanya menggunakan sumber daya CPU sampai $4 \%$ yaitu pada penerapan LVS-NAT dengan 2 server menggunakan algoritma round robbin.

b. Web server yang menggunakan implementasi load balancing LVS-NAT algoritma least connection 4 server paling sedikit menggunakan sumber daya CPU yaitu berkisar antara 2\%-3\%.

\section{KESIMPULAN}

Setelah melakukan implementasi load balancing web server menggunakan Linux Virtual Server dengan metode LVS-NAT, pengujian kinerja web server hasil implementasi load balancing tersebut, serta membandingkannya dengan kinerja web server tunggal maka didapatkan kesimpulan sebagai berikut :

a) Implementasi load balancing web server menggunakan LVS-NAT mampu meningkatkan nilai throughput web server dengan besaran yang cukup signifikan hingga 2 kali lipat throughput web server tunggal. Nilai ini diperoleh pada implementasi LVS dengan 4 real server menggunakan algoritma round robbin dengan throughput sebesar 69,28 replies/second. Peningkatan throughput web server sejalan dengan peningkatan jumlah real server yang digunakan dalam LVS. Throughput web server dengan LVS 2 real server baik itu yang menggunakan algoritma Round Robbin 
Jefry Alvonsius Rabu, Joko Purwadi, Willy S. Raharjo

53,78 replies.second maupun Least Connection 45,08 replies/second lebih kecil dari throughput web server dengan LVS 4 real server menggunakan algoritma Round Robbin 69,28 replies/second dan Least Connection 47,96 replies/second.

b) Implementasi load balancing web server menggunakan LVS-NAT mampu meningkatkan response time dan mengoptimalkan CPU Utilization dari web server namun peningkatan yang dihasilkan memiliki nilai yang tidak terlalu besar sehingga dianggap tidak terlalu signifikan.

c) Implementasi LVS-NAT menggunakan algoritma round robbin lebih handal dalam mengoptimalkan throughput, CPU Utilization, dan response time dari web server jika dibandingkan dengan implementasi LVS-NAT menggunakan algoritma least connection.

\section{Daftar Pustaka}

Arlitt, M., \& Williamson, C. (2004). Understanding Web Server Configuration Issues. Canada : Department of Computer and Science, University of Calgary.

Bourke, T. (2001). Server Load Balancing. O’Reilly \& Associates, Inc., Sebastopol.

Gourley, D., Totty, B., Sayer, M., Sailu, R., \& Aggarwal, A. (2002). HTTP - The Definitive Guide. Q'Reilly.

Kim, M., Choi, M., \& Hong, J., Highly Available and Efficient Load Cluster Management System using SNMP and Web. Dept. of Computer Science andEngineering, POSTECH Pohang, Korea.

Utdirartatmo, F. (2004). Clustering PC di Linux dengan OpenMosix dan ClusterKnoppix, Yogyakarta: Penerbit ANDI.

Tanenbaum, S. (2003). Computer Networks - Fourth Edition. Prentice Hall.

Zhang, W. (2004). Linux Virtual Server for Scalable Network Service, http://www.linuxvirtualserver.org/, diakses tanggal 16 April 2011

Zhang, W., Jin, S., \& Wu, Q...(2004). Creating Linux Virtual Servers. Hunan-China: National Laboratory for Parallel and Distributed Processing. 